\title{
HEDONISMO E MORALISMO: CONSUMO NA BASE DA PIRÂMIDE
}

HEDONISM AND MORALISM: THE BOTTOM OF THE PYRAMID

HEDONISMO Y MORALISMO: EN EL CONSUMO EN LA BASE DE LA PIRÁMIDE

\section{RESUMO}

A estabilidade econômica no Brasil permitiu que itens acessíveis somente às classes sociais mais abastadas fossem consumidos na "base da pirâmide". Tal fato despertou interesse acadêmico e empresarial por melhor compreender esse fenômeno. Duas linhas argumentativas surgiram, com distintas perspectivas. Enquanto uma defende um discurso hedonista, ao incentivar o consumo pela base da pirâmide, como forma de diminuir a pobreza, a outra, cuja perspectiva dominante é moralista, critica tal visão, pois acredita que somente a inserção das pessoas com menor poder aquisitivo no processo de produção contribuirá para melhorar suas vidas.. Um dos objetivos do presente ensaio é, portanto, discutir como a literatura sobre o consumo na base da pirâmide apresenta elementos desses tipos de discursos. Além disso, busca-se estimular mais estudos, propondo uma agenda inicial de pesquisa

PALAVRAS-CHAVE Hedonismo, moralismo, pobreza, consumo, renda.

Marcus Wilcox Hemais mhemais@gmail.com

Doutorando em Administração de Empresas pelo Instituto Coppead de Administração - Universidade Federal do Rio de Janeiro; e Professor do Instituto de Administração e Gerência, Pontifícia Universidade Católica do Rio de Janeiro - Rio de Janeiro - RJ, Brasil

Leticia Moreira Casotti leticia@coppead.ufrj.br

Professor do Instituto Coppead de Administração, Universidade Federal do Rio de Janeiro - Rio de Janeiro - RJ, Brasil

Everardo Pereira Guimarães Rocha everardo@puc-rio.br

Professor do Departamento de Comunicação Social, Pontifícia Universidade Católica do Rio de Janeiro - Rio de Janeiro - RJ, Brasil

Abstract Economic stability in Brazil has allowed items that were formerly only accessible to the better-off social classes, to be consumed at "the bottom of the pyramid". This has aroused the interest of both the academic and business world and led to a desire for a better understanding of this phenomenon. Two lines of argument have arisen with distinct perspectives. The first supports a hedonistic approach, which believes that consumption at the base of the pyramid is driven by a wish to reduce poverty, while the other, where a moralistic standpoint is predominant, criticizes this view because it believes that people's lives can only be improved by including people with less purchasing power in the production processes. One of the aims of this essay is thus to discuss how the literature on consumption at the bottom of the pyramid, shows features of these types of approaches. In addition, it seeks to encourage further studies by setting out a research agenda. keywords Hedonism, moralism, poverty, consumption, income.

Resumen La estabilidad económica en Brasil permitió que artículos accesibles solamente a las clases sociales más adineradas fueran consumidos por la "base de la pirámide". Tal hecho despertó el interés académico y empresarial para comprender mejor ese fenómeno. Surgieron dos líneas argumentativas, con distintas perspectivas. Mientras una defiende un discurso hedonista, al incentivar el consumo por la base de la pirámide como forma de disminuir la pobreza, la otra, cuja perspectiva dominante es moralista, critica tal visión, pues considera que solamente la inserción de las personas con menor poder adquisitivo en el proceso de producción contribuirá a mejorar sus vidas. Uno de los objetivos del presente ensayo es, por lo tanto, discutir cómo la literatura sobre el consumo en la base de la pirámide presenta elementos de esos tipos de discursos. Además, se busca estimular más estudios, proponiendo una agenda inicial de investigación.

Palabras clave Hedonismo, moralismo, pobreza, consumo, renta. 


\section{INTRODUÇÃO}

O interesse acadêmico em consumidores de baixa renda data desde a década de 1960, sendo David Caplovitz (1967) um dos primeiros estudiosos sobre o assunto. O tema continuou a ser pesquisado, especialmente nos Estados Unidos, durante a década de 1970 (ANDREASEN, 1976), ao mesmo tempo que cresciam debates sobre consumerismo (KOTLER, 1972). Essa temática foi posta em segundo plano, todavia, à medida que o movimento consumerista perdia suas forças.

O tema voltou a ganhar destaque no meio acadêmico, no início dos anos 2000, a partir dos estudos de C. K. Prahalad (PRAHALAD e HAMMOND, 2002; PRAHALAD e HART, 2002). O livro do autor (PRAHALAD, 2006a) foi listado entre os mais vendidos em importantes revistas e livrarias americanas e inglesas, mostrando sua relevância na divulgação do tema (LANDRUM, 2007). Prahalad chamava a atenção para o fato de haver quatro bilhões de pobres no mundo, na "base da pirâmide", com rendimento de até dois dólares por dia. Mesmo que suas condições de consumo fossem restritas, seu volume representava uma oportunidade única de mercado para empresas, que, além de lucrar, ajudariam esses indivíduos a saírem da pobreza.

Após Prahalad, discussões sobre quem são aqueles que compõem a base da pirâmide passaram a ser vistas na literatura (SACHS, 2005). No Brasil, por exemplo, diferentes critérios existem para estratificar classes sociais ou econômicas. A Pesquisa Nacional por Amostra de Domicílios (PNAD), realizada pelo IBGE, leva em consideração a renda média mensal domiciliar para classificar a população em seis estratos (INSTITUTO..., 2009). Com base no PNAD, a Fundação Getulio Vargas (FGV) transforma os seis estratos em cinco, dividindo-os em classes A, B, C, D e E (NERI, 2010). O Critério de Classificação Econômica Brasil, elaborado pela Associação Brasileira de Empresas de Pesquisa (ABEP), por sua vez, considera a posse de bens e o grau de instrução do chefe do domicílio para estratificar a população em oito classes econômicas: A1, A2, B1, B2, C1, C2, D e E (ASSOCIAÇÃO..., 2012).

Entender quais classes sociais constituem a base da pirâmide ou mesmo a população de baixa renda no Brasil tem se mostrado um desafio para pesquisadores (MATTOSO, 2010; NOGAMI e PACAGNAN, 2011). A classe C, por exemplo, pode ser incluída na base da pirâmide (LIMEIRA, 2008) ou ser considerada "a nova classe média" (NERI, 2010). Consciente de tais dificuldades, o Centro de Excelência em Varejo da Fundação
Getulio Vargas (CEV-FGV) definiu consumidores de baixa renda, no Brasil, como aqueles pertencentes às classes D e E, segundo classificação do IBGE, ou seja, com renda familiar diária inferior a cinco dólares (NOGAMI e PACAGNAN, 2011).

Essas discussões e divergências sugerem a dificuldade e a crescente importância em entender as classes inferiores do estrato social, também chamadas de "base da pirâmide", conforme Prahalad, ou de "baixa renda". Embora importante, não é o foco do ensaio, entretanto, debater as diferenças entre classificações. O que se pretende é discutir o aumento do interesse em torno do consumo na base da pirâmide e as críticas que surgiram em relação ao tema.

Após Prahalad proferir sua visão sobre a base da pirâmide, autores questionam se a ideia e a forma proposta para erradicar a pobreza servem, na realidade, a esse fim (ARORA e ROMIJN, 2011; KARNANI, 2007a, 2011; JAISWAL, 2008). Para os defensores dessa perspectiva, o incentivo ao consumo na base da pirâmide não soluciona o problema da pobreza, e as grandes empresas multinacionais não devem autoproclamar-se como salvadoras da sociedade.

As críticas feitas por Karnani geraram um interessante debate, entre ele e Prahalad, sobre a validade da proposta de incentivo ao consumo na base da pirâmide. Durante esse debate, Prahalad diz que:

Estou surpreso que você [Karnani] tenha caído na
mesma armadilha em que a maioria cai. O consumo
pode aumentar a renda... O tempo dirá se a base da
pirâmide é um mercado ou não. Eu acredito que é...
O debate não é mais sobre quantos indivíduos são
realmente pobres; é sobre como trazer os benefícios
dos padrões globais a preços acessíveis, de modo a au-
mentar o acesso (PRAHALAD, 2006b, tradução nossa).

e Karnani alega que:

Uma crítica à proposta da base da pirâmide é que tratar o pobre como um consumidor pode levá-los a fazerem más escolhas de consumo, que não são de seu interesse próprio. Assim, empresas poderiam acabar explorando esses pobres. Os proponentes da base da pirâmide ignoram tais argumentos, por considerá-los arrogantes e condescendentes, e afirmam que os pobres são consumidores conscientes (KARNANI, 2007b, tradução nossa).

As duas perspectivas sobre o consumo na base da 
pirâmide podem ser diferenciadas com base em seus discursos. De acordo com Rocha (2005, 2009b), discursos sobre consumo podem ser do tipo "hedonista" ou "moralista". O primeiro representa o consumo como algo necessário para se atingir a felicidade e o sucesso, e o segundo o apresenta como a principal causa dos males da sociedade.

Com base nessa contextualização, o presente ensaio discute as distintas perspectivas sobre o consumo na base da pirâmide, utilizando a nomenclatura proposta por Rocha. Autores defensores do incentivo ao consumo na base da pirâmide utilizam discursos predominantemente "hedonistas", e os que criticam essa perspectiva apresentam discursos essencialmente "moralistas". O principal objetivo deste ensaio, portanto, é discutir como a literatura sobre o consumo na base da pirâmide apresenta elementos desses tipos de discursos, além de propor uma agenda de pesquisa mais específica para a realidade brasileira.

\section{OS DISCURSOS HEDONISTA E MORALISTA DE CONSUMO}

Um dos primeiros autores a tratar do tema de consumo foi Thorstein Veblen, em 1899. O autor defendia que o consumo era um fenômeno que não poderia ser enquadrado dentro de modelos econômicos tradicionais e que, por isso, deveria ser visto como algo fora desses padrões. O consumo conspícuo seria o substituto do ócio como a atividade que transmitiria características pessoais de cada indivíduo a seus pares (VEBLEN, 1965).

Depois de Veblen, outros autores, dentro das ciências sociais, continuaram a estudar o consumo (BOURDIEU, 2007; DOUGLAS e ISHERWOOD, 2009; MCCRACKEN, 2003). Em comum entre eles, está a ideia de que o consumo se relaciona com cultura e valores sociais. Qualquer teorização sobre o consumo precisa ser, também, uma teorização sobre a cultura e a vida social (DOUGLAS e ISHERWOOD, 2009). Sem o consumo, "certos atos de definição do self e de definição coletiva seriam impossíveis" (McCRACKEN, 2003, p. 11). O consumo, por essa perspectiva, ajuda a definir a cultura e os valores dos indivíduos de uma sociedade.

No Brasil, a preocupação em entender as dinâmicas relacionadas ao consumo levou Rocha (2005, 2009b) a analisar os tipos de discursos existentes sobre o tema. O autor identificou quatro principais tipos: hedonista, moralista, naturalista e utilitarista. Como a proposta do presente trabalho é mostrar dois extremos dos discursos sobre o consumo na base da pirâmide, optou-se por focar os dois primeiros. O discurso naturalista não se enquadra nesse caso, pois busca explicar o consumo como algo que existe em razão de necessidades "da natureza, da biologia ou do espírito humano" (ROCHA, 2005, p. 131). Similarmente, o discurso utilitarista foge ao escopo desejado no presente ensaio, pois sua função é compreender o consumo por meio de estudos e pesquisas que gerem maior conhecimento gerencial sobre como vender mais.

Rocha (2005, 2009b) observa que o discurso hedonista é a ideologia mais conhecida sobre o consumo. O autor afirma que esse discurso caracteriza o consumo como um meio para se chegar ao sucesso e à felicidade. Assim, o consumo é descrito como uma forma de gratificação imediata, que dá sentido à vida e se torna uma "espécie de passaporte para a eternidade, consumir freneticamente é ter a certeza de ser um peregrino em viagem ao paraíso" (ROCHA, 2005, p. 127). Apesar de o consumo possuir associações a conotações negativas, tais como materialismo e individualismo, Miller (2001) acredita que o sofrimento e as dificuldades pelas quais os indivíduos passam atualmente são resultado direto da falta de bens. O consumo, logo, seria uma forma de atenuar tais sentimentos.

O processo contínuo de procurar, comprar, saborear, usar e descartar um bem ou um serviço é, no fundo, uma busca por laços sociais. O consumo, portanto, permite que relações entre indivíduos sejam criadas e mantidas. A partir do momento em que se possui um bem, o indivíduo torna-se integrante de um grupo, que compartilha valores e pensamentos semelhantes (BOURDIEU, 2007).

Diferentemente dessa visão, o discurso moralista responsabiliza o consumo por variados tipos de problemas da sociedade (ROCHA, 2009b). De acordo com esse discurso, o consumo leva os indivíduos a terem atitudes impensadas, cujas consequências podem ser drásticas para a sociedade. Logo, o estímulo ao consumo é um mal que precisa ser combatido. Autores que utilizam o discurso moralista sobre o consumo acreditam que possuem o dever de defender a correta orientação da sociedade, chamando a atenção aos males que o consumo pode causar. Falar mal do consumo, nesse contexto, torna-se politicamente correto, já que se trata de um fenômeno alienador, individualista e restrito a poucos (ROCHA, 2005).

Por trás do discurso moralista, está uma ideologia que vê a produção como atividade superior ao consumo. Enquanto o conceito de produção é visto como positivo, 
associado a construir e trabalhar, atos que engrandecem o ser humano, o conceito de consumir é visto como negativo, uma praga que deve ser repelida, por remeter a excessos e banalidades (ROCHA, 2005).

As duas diferentes correntes de pensamento sobre o consumo mostram como o tema pode inspirar pontos de vista diversos. Esses mesmos contrastes podem ser vistos também quando o objeto de análise é o consumo nas camadas mais baixas da sociedade. As seções seguintes mostram como o discurso hedonista e o discurso moralista são encontrados em textos sobre o consumo na base da pirâmide.

\section{O DISCURSO HEDONISTA DE CONSUMO NA BASE DA PIRÂMIDE}

Até há pouco mais de uma década, quando se falava em consumo, remetia-se mais às camadas abastadas da sociedade, com a justificativa de que somente estas possuíam condições financeiras para consumir produtos hedônicos. Os indivíduos de baixa renda sequer eram vistos como consumidores, pois a percepção predominante era de que consumiam somente o necessário para sobreviver (BARROS, 2006a).

Essa percepção - acadêmica e empresarial - está mudando, à medida que consumidores de baixa renda têm consumido mais, especialmente após a estabilidade econômica de diversos países em desenvolvimento, tais como o Brasil, já que seu poder aquisitivo aumentou (ROCHA, 2009a). Apesar de a renda média desses consumidores ser menor do que a dos de classes mais abastadas, seu poder de compra é elevado, devido à grande quantidade de pessoas que se encontram nessa situação (PRAHALAD, 2006a).

Empresas e pesquisadores passaram a enxergar consumidores de baixa renda com outros olhos, desde então, em função do seu "novo" poder de consumo. Os antes excluídos, agora, são vistos como uma "fortuna na base da pirâmide" (PRAHALAD e HART, 2002). Em vez de representarem um problema social, cuja responsabilidade em acudir é do Estado, esses indivíduos devem ser tratados como consumidores, cuja responsabilidade em atender é das grandes empresas (PRAHALAD, 2006a).

Segundo essa perspectiva, grandes empresas deveriam adaptar seus bens e serviços às realidades mais restritas desse público, se desejam aproveitar oportunidades na base da pirâmide. A balança, então, equilibrar-se-ia, pois os consumidores abraçariam as empresas que melhor os atendessem, as quais, por sua vez, ajudariam a elevar os padrões de vida desses indivíduos (PRAHALAD, 2006a). Além de lidar com o problema da pobreza mundial, tais práticas também servem para combater a estagnação econômica, deflação, falhas do governo e, até, guerras civis e terrorismo (PRAHALAD e HAMMOND, 2002).

Para reforçar essas ideias, casos de sucesso de empresas que foram bem-sucedidas ao se voltarem para a população de baixa renda, tais como Banco Graamen, Cemex, Nestlé e Unilever, passaram a ser documentados em publicações sobre o consumo na base da pirâmide (ALTMAN, REGO, ROSS, 2009; PRAHALAD, 2006a; WOOD, PITTA, FRANZAK, 2008). Hammond e Prahalad (2004), por exemplo, citam o caso da Hindustan Lever e da Procter \& Gamble, na Índia, que aumentaram suas vendas de xampus quando adaptaram suas embalagens, tornando-as menores, voltadas especialmente para consumidores de baixa renda. O preço do produto, em consequência, foi reduzido, o que possibilitou a sua aquisição por parte desse segmento de mercado. De acordo com os autores, além de proporcionar a "quase todos os indianos a possibilidade de desfrutar de acesso a xampu" (HAMMOND e PRAHALAD, 2004, p. 35, tradução nossa), essas empresas ajudaram a expandir o mercado e gerar maior acesso a bens e serviços, o que melhorou a qualidade de vida dos indivíduos.

No Brasil, Prahalad (2006a) cita o sucesso das Casas Bahia. Um dos fatores responsáveis por impulsionar o crescimento da empresa, ao mesmo tempo que ajudou a melhorar a qualidade de vida de seus clientes, foi a venda por meio de crediário: $90 \%$ de todas as suas vendas são feitas com essa forma de pagamento. Barros e Rocha (2009) apontam que, para consumidores de baixa renda, o parcelamento das compras é uma opção "atraente por permitir à pessoa adquirir vários bens ao mesmo tempo ou, ainda, por colocar em prática estratégias que permitam a realização de alguns desejos de consumo" (Barros e Rocha, 2009, p. 37).

A possibilidade de consumir produtos que antes eram restritos a classes mais altas faz com que consumidores de baixa renda passem a admirar empresas que se dedicam a vender para a base da pirâmide. De acordo com Barros e Rocha (2009), os fatores que mais contribuem para nutrir tal admiração são a facilidade de acesso a crédito e o bom atendimento. Trechos de entrevistas, tirados do trabalho de Barros e Rocha, reforçam essa ideia, quando consumidores dizem que as Casas Bahia "se dedicam mesmo, abrem o coração", "são como uma mãe, facilita pra gente", "só falta dar 
as coisas", e "sou sempre bem atendida lá" (Barros e Rocha, 2009, p. 41).

A importância que consumidores de baixa renda dão à compra é vista por Castilhos e Rossi (2009) e Barros e Rocha (2009) como uma forma de "consumo de pertencimento". A posse de tais bens possibilita que esses indivíduos tenham acesso à "sociedade de consumo" e, ao mesmo tempo, troquem a identidade de "pobre" pela de "consumidor". Por dar valor à sua dignidade (BARKI e PARENTE, 2010), incentivar esses indivíduos a consumir, portanto, é uma forma de dar-lhes poder (BONSU e POLSA, 2011).

O prazer dos consumidores de baixa renda em consumir pode também ser entendido como um desejo de participar dos benefícios que a sociedade de consumo lhes pode proporcionar (BARROS, 2006b). Barros (2006b, p. 9) argumenta que a falta de conhecimento sobre os valores associados ao consumo na base da pirâmide não permite que se perceba "a grande ênfase que [consumidores de baixa renda] colocam na cultura material". Por meio da posse, esses consumidores podem distinguir-se dos "mais pobres ainda" e imaginar que estão em vias de pertencer ao "mundo dos ricos".

Castilhos e Rossi (2009, p. 69) observam que "é pelo consumo, não pelo trabalho" que consumidores de baixa renda se diferenciam dos "pobres-pobres", que não possuem uma casa ou o que comer. A posse de determinados bens, tais como automóveis, propriedades, computadores pessoais, aparelhos de DVD e televisores de 29 polegadas, é vista por moradores de uma determinada favela, em Porto Alegre, como uma afirmação de que possuem uma melhor condição de vida.

As características do discurso hedonista, presentes na literatura que defende o incentivo ao consumo na base da pirâmide, mostram um lado glamoroso, em que empresas e sociedade podem beneficiar-se com o aumento do consumo para os pobres. Entretanto, esse não é o único discurso que aborda o tema. A seção seguinte analisará um segundo discurso, cuja principal característica é ser mais conservador e questionador em relação aos benefícios do incentivo ao consumo na base da pirâmide.

\section{O DISCURSO MORALISTA DE CONSUMO NA BASE DA PIRÂMIDE}

As ideias defendidas inicialmente por Prahalad começaram a sofrer críticas de uma linha de pensamento que não acredita que o incentivo ao consumo na base da pirâmide possa ser lucrativo ou a forma ideal para grandes empresas ajudarem a diminuir a pobreza. Autores que defendem essa visão "moralista" sobre o consumo questionam Prahalad e propõem outra solução para melhorar a qualidade de vida na base da pirâmide.

Karnani (2007a) rejeita os dados, apresentados por Prahalad (2006a), de que existem quatro bilhões de consumidores na base da pirâmide, com rendimentos de dois dólares por dia, e argumenta que, na verdade, os mercados na base da pirâmide são pequenos e pouco lucrativos. O autor salienta que gastos de comercialização para esses consumidores são altos, devido à sua grande dispersão geográfica; e economias de escala, impossíveis de se obterem, por causa de sua diversidade cultural. Além disso, 80\% dos gastos de consumidores na base da pirâmide são com alimentos, vestuário e combustível, restando-lhes pouco dinheiro para ser gasto com outros produtos, de natureza hedônica. Para Karnani (2007a, p. 108, tradução nossa), a fortuna na base da pirâmide nada mais é do que uma "miragem".

O incentivo ao consumo na base da pirâmide é uma forma de empresas usarem ações de marketing para influenciar os hábitos desses consumidores, de modo que passem a gastar mais com produtos hedônicos (GER, 1992). As consequências disso, quando os consumidores em questão são pobres, podem ser desastrosas, pois o dinheiro gasto em produtos hedônicos reduz os recursos destinados a produtos essenciais (DAVIDSON, 2009).

Empresas interessadas em vender para consumidores na base da pirâmide não devem, de acordo com Davidson (2009), praticar altas margens de lucro, baseando-se nos mesmos rendimentos de quando vendem para consumidores no topo da pirâmide. O preço de bens oferecidos à base da pirâmide deve possibilitar que consumidores nesse segmento tenham condições de comprá-los, melhorando, assim, sua qualidade de vida.

Empresas que vendem para consumidores na base da pirâmide possuem uma vantagem sobre eles, por causa do baixo grau de educação formal que esses indivíduos possuem. Táticas empresariais consideradas éticas em países desenvolvidos, portanto, não podem simplesmente ser transferidas para mercados subdesenvolvidos ou emergentes, onde grande parte dos consumidores possui baixa renda (DAVIDSON, 2009).

Enquanto Prahalad (2006a) argumenta que consumidores nesses países possuem o direito de determinar como gastam seus rendimentos, pois são conscientes de suas escolhas, Karnani (2007a) coloca-se contra a proposta de livre mercado ou de livre escolha, pois a aplicação desses princípios em outros países, onde a 
maior parte da população está na base da pirâmide, pode trazer implicações perigosas.

De acordo com Jaiswal (2008), casos de empresas que não tiveram sucesso na tentativa de atender a base da pirâmide dificilmente são encontrados na literatura. Comumente, o que se retrata são as iniciativas bem-sucedidas. O autor argumenta, entretanto, que mesmo os casos de sucesso não refletem uma realidade universal sobre os mercados da base da pirâmide, já que são relatos de empresas que atuam em economias cujos crescimentos, nos últimos tempos, têm sido acelerados, tais como Índia, Brasil e México. Relatos de empresas bem-sucedidas em países com pouco desenvolvimento são difíceis de encontrar.

O discurso moralista critica a visão de livre mercado ou de livre escolha por ignorar questões políticas e éticas sobre o consumo na base da pirâmide. Quando Prahalad (2006a) se refere a pobres, ele os coloca em um mesmo grupo de quatro bilhões, cujo elo comum é a pobreza. Chatterjee (2009) argumenta, entretanto, que essa condição socioeconômica varia de acordo com contextos históricos, culturais e políticos. Um entendimento descontextualizado sobre a pobreza "esvazia a vida dos 'pobres' de suas ricas histórias de dificuldades e sobrevivência" (Chatterjee, 2009, p. 6, tradução nossa), reforçando uma imagem estereotipada desses indivíduos.

Segundo Karnani (2011), a visão "romantizada" do consumidor na base da pirâmide, trazida pela corrente de pensamento aqui denominada "hedonista", faz com que os Estados criem poucas leis, regulações e mecanismos sociais para proteger esses indivíduos e, ao mesmo tempo, confiem demasiadamente nas soluções do mercado para resolver os problemas relacionados à pobreza. Para o autor, os governos devem prevenir a exploração dos pobres, já que esses indivíduos enfrentam realidades sociais, psicológicas, físicas e econômicas diferentes daqueles com condições mais abastadas.

O discurso crítico sobre a proposta de estimular o consumo na base da pirâmide retrata o consumidor como refém das grandes empresas, já que, de acordo com Banerjee e Duflo (2011), esses indivíduos não possuem controle sobre seus impulsos, facilmente caem em tentação e gastam com o intuito de impressionarem seus vizinhos. Essas características de consumo também podem ser vistas em consumidores que possuem mais recursos financeiros, porém as consequências de escolhas ruins podem ser mais severas para os menos favorecidos.

O pessimismo quanto ao incentivo ao consumo na base da pirâmide como solução para a pobreza levou autores dessa linha "moralista" a proporem uma respos- ta alternativa para esse problema. Nessa visão, a única maneira para melhorar a qualidade de vida dos pobres seria aumentando seus rendimentos (KARNANI, 2007a, 2011; JAISWAL, 2008). A forma para se alcançar isso seria incluí-los no sistema produtivo de bens e serviços e, assim, eles comprariam o que fosse fabricado por eles mesmos. Os pobres, portanto, passariam a ser vistos como investidores, empreendedores e produtores, e não como consumidores.

Dessa forma, governos, por meio de empresas, seriam responsáveis pelo êxito de tal iniciativa. O setor privado serve a esse propósito apenas como um caminho pelo qual empregos podem ser criados. A melhora na qualidade de vida de indivíduos na base da pirâmide passa, segundo essa perspectiva, por melhores condições de trabalho. Somente incentivar consumidores de baixa renda a adquirirem mais bens e serviços não lhes traria benefícios, porque o aumento da posse de bens não significa aumento de renda.

\section{CONSIDERAÇÕES FINAIS: UMA AGENDA INICIAL DE PESQUISA}

O presente ensaio apresentou diferentes perspectivas na literatura sobre o consumo na base da pirâmide. As duas principais abordagens identificadas possuem características do que Rocha $(2005,2009 b)$ chama de discursos hedonista e moralista de consumo.

O discurso daqueles favoráveis ao incentivo ao consumo na base da pirâmide sugerem diferentes benefícios: às empresas, quando fala sobre lucratividade, fortunas e oportunidades de negócios; à sociedade, por ser uma forma de combater guerras e terrorismo; e, também, à população de baixa renda, ao argumentar que proporciona melhoria da qualidade de vida e felicidade pela gratificação imediata trazida pelo consumo.

Diferentemente, os que discordam desse caminho escrevem sobre miragem, tentações, empresas manipulando consumidores e consumidores reféns, impulsivos. Embora não se oponha ao consumo, o discurso moralista responsabiliza o fenômeno consumista pelos problemas sociais, especialmente aqueles que afetam o consumidor de baixa renda. Por possuírem restritas condições financeiras e sofrerem de falta de bens essenciais, tais indivíduos são os que mais sofrem com o incentivo ao consumo proposto pela corrente hedonista.

Essa abordagem ressalta, também, as restrições de recursos financeiros e a falta de bens essenciais como 
consequências severas para consumidores de baixa renda. Predomina, assim, um discurso que responsabiliza o fenômeno consumista pelos problemas sociais.

O intuito, aqui, não é defender uma forma ou outra de discurso sobre o consumo na base da pirâmide. Acredita-se, porém, que ambos os caminhos discutidos possuem elementos que convidam a uma reflexão cuidadosa sobre o tema, especialmente no contexto brasileiro. Nesse segmento, foi verificado um crescente acesso a novos bens e serviços.

Poucos são os estudos, todavia, que buscam aprimorar conhecimento e sensibilidade em relação a aspirações, sentimentos e comportamentos dos consumidores da base da pirâmide. Algumas pesquisas sobre esse segmento, no Brasil, tais como as de Barros (2006b), Barros e Rocha (2009) e Castilhos e Rossi (2009), sugerem que o consumo pode ser uma forma de inclusão social e melhora na qualidade de vida dos pobres; que o ato de consumir lhes oferece um sentimento de pertencimento à "sociedade de consumo" e uma perspectiva de que, com isso, serão mais felizes. Argumenta-se, assim, que a possibilidade de consumir é uma forma de proporcionar mais dignidade à vida da população de baixa renda. Cabe refletir, entretanto, se essa dignidade é uma sensação que pode se perder em curto prazo.

O significado de consumir traz uma conotação quase imediatista. Por essa visão, o incentivo ao consumo como objetivo para diminuir a pobreza pode ser considerado uma ação de duração rápida, pois não busca solucionar as causas estruturais desse problema. Somente o aumento da quantidade de bens em posse de um indivíduo de baixa renda não significa que ele esteja fora da faixa de pobreza.

O incentivo ao consumo na base da pirâmide pouco discute a sustentabilidade de tal ato (FARIAS e FARIAS, 2010). Parece, dessa forma, simplificar o combate à pobreza, sugerindo que esse problema pode ser resolvido no curto prazo, apenas aumentando a posse de bens de um consumidor. Defende-se aqui, portanto, um olhar de marketing que se preocupe com o longo prazo e com lucros e comportamentos sustentáveis.

O discurso hedonista defendido por Prahalad (2006a) incentiva o consumo na base da pirâmide por meio de princípios de livre mercado ou de livre escolha, comumente adotados nos Estados Unidos, destacando que essa é a melhor solução para diminuir a pobreza e melhorar a qualidade de vida dos pobres. No Brasil, a possibilidade de comprar uma geladeira ou um fogão, nas Casas Bahia, também parece melhorar a autoestima de consumidores de baixa renda. Entretanto, para sair da pobreza, esses indivíduos precisam ter acesso a serviços básicos que exigem pensamento e investimento de longo prazo, cuja responsabilidade é do Estado, tanto do americano quanto do brasileiro.

Os debates sobre o valor do consumo na base da pirâmide estão apenas começando. Para que tais estudos sejam aprofundados, acredita-se que pesquisadores da área de marketing e, mais especificamente, de comportamento do consumidor devem dar mais atenção ao tema. Dessa forma, para que esses debates ganhem realidade, propõe-se uma agenda inicial de pesquisa, a fim de que se possa avançar no conhecimento sobre uma população tão importante, no Brasil, tanto para governos quanto para empresas. Sugere-se, então, que futuras pesquisas busquem:

- Conhecer o comportamento de consumo da população na base da pirâmide, de modo a enxergar a diversidade existente nesse segmento;

- Conhecer os principais significados e sentimentos que envolvem o consumo na base da pirâmide;

- Compreender quais benefícios e/ou problemas a população de baixa renda enxerga nos diferentes tipos de incentivo ao consumo na base da pirâmide;

- Compreender como o consumo e o trabalho participam da formação da identidade de indivíduos na base da pirâmide;

- Diferenciar o comportamento do consumidor de baixa renda de grandes centros urbanos, de cidades menores ou, até, do meio rural;

- Compreender como consumidores de baixa renda percebem as políticas governamentais de incentivo ao consumo, seja pela facilitação ao acesso ao crédito ou por programas assistencialistas;

- Compreender como ocorrem a difusão e a adoção de inovações em bens e serviços por consumidores desse segmento e como tais inovações contribuem para a sustentabilidade do consumo na base da pirâmide;

- Buscar métodos de pesquisa, tais como técnicas projetivas e história de vida, que sejam adequados para entender práticas e significados associados a esses consumidores.

Cabe observar, ainda, que, no Brasil, as experiências em pesquisar consumidores de baixa renda sugerem poucas dificuldades de acesso a essa população que, por muito tempo, quase não vivenciou a experiência de ser ouvida. Tal fato sugere que indivíduos desse segmento estão aptos a serem observados, perguntados e 
a falar sobre si mesmos, o que pode servir como mais um incentivo para aqueles que se motivarem a seguir ou ampliar essa sugestão de agenda de pesquisa.

\section{REFERÊNCIAS}

ALTMAN, D; REGO, L; ROSS, P. Expanding opportunity at the base of the pyramid. People \& Strategy, v. 32, n. 2, p. 46-51, 2009.

ANDREASEN, A. The differing nature of consumerism in the ghetto. Journal of Consumer Affairs, v. 10, n. 2, p. 179-190, 1976.

ARORA, S; ROMIJN, H. The empty rhetoric of poverty reduction at the base of the pyramid. Organization, v. 18, n. 4, p. 1-25, 2011.

ASSOCIAÇÃO BRASILEIRA DE EMPRESAS DE PESQUISA. Critério de classificação econômica Brasil. Disponível em: http://www.abep.org/novo/Content.aspx?ContentID=301. Acesso em 20.10.2012.

BANERJEE, A; DUFLO, E. Poor economics: a radical rethinking of the way to fight global poverty. New York: Public Affairs, 2011. 303 p.

BARKI, E; PARENTE, J. Consumer behavior of the base of the pyramid marketing in Brazil. Greener Management International, v. 56, p. 11-23, 2010.

BARROS, C. A "invisibilidade" do mercado de baixa renda nas pesquisas de marketing. In: ENCONTRO DE MARKETING DA DA ASSOCIAÇÃO NACIONAL DOS PROGRAMAS DE PÓS-GRADUAÇÃO EM ADMINISTRAÇÃO, 2, 2006, Rio de Janeiro. Anais. Rio de Janeiro: ANPAD, 2006a.

BARROS, C. Consumo, hierarquia e mediação: um estudo antropológico no universo das empregadas domésticas. In: ENCONTRO NACIONAL DA ASSOCIAÇÃO NACIONAL DOS PROGRAMAS DE PÓS-GRADUAÇÃO EM ADMINISTRAÇÃO, 30, 2006, Salvador. Anais. Salvador: ANPAD, 2006b.

BARROS, C; ROCHA, E. Lógica de consumo em um grupo das camadas populares: uma visão antropológica de significados culturais. In: ROCHA, A; SILVA, J. (Orgs). Consumo na base da pirâmide: estudos brasileiros. Rio de Janeiro: Mauad X, 2009. 255 p.
BONSU, S; POLSA, P. Governmentality at the base-of-the-pyramid. Journal of Macromarketing, v. 31, n. 3, p. 236244, 2011.

BOURDiEU, P. A distinção: critica social do julgamento. Porto Alegre: Zouk, 2007. 560 p.

CAPLOVITZ, D. The poor pay more. New York: The Free Press, 1967. $225 \mathrm{p}$.

CASTILHOS, R; ROSSI, C. A. Subindo o morro: consumo, posição social e distinção entre famílias de classes populares. In: ROCHA, A; SILVA, J. (Orgs). Consumo na base da pirâmide: estudos brasileiros. Rio de Janeiro: Mauad X, 2009. 255 p.

CHATTERJEE, S. "Selling to the poor": reflections, critique, and dialogue. Disponível em: http://www.cba.ufl.edu/academics/pdbp/docs/proposals/2009_SuparnaChatterjee.pdf. Acesso em 09.11.2009.

DAVIDSON, K. Ethical concerns at the bottom of the pyramid: where CSR meets BOP. Journal of International Business Ethics, v. 2, n. 1, p. 22-32, 2009.

DOUGLAS, M; ISHERWOOD, B. O mundo dos bens: para uma antropologia do consumo. 1. ed, 2. reimpr. Rio de Janeiro: UFRJ, 2009. 306 p.

FARIAS, C; FARIAS, G. Cycles of poverty and consumption: the sustainability dilemma. Competitive Review: An International Business Journal, v. 20, n. 3, p. 248-257, 2010.

GER, G. The positive and negative effects of marketing on socioeconomic development: the turkish case. Journal of Consumer Policy, v. 15, n. 3, p. 229-254, 1992.

HAMMOND, A; PRAHALAD, C. K. Selling to the poor. FOreign Policy, p. 30-37, May/June 2004.

HOPPEN, N. e outros. Sistemas de informação no Brasil: uma análise dos artigos científicos dos anos 90. In: ENCONTRO NACIONAL DA ASSOCIAÇÃO NACIONAL DOS PROGRAMAS DE PÓS-GRADUAÇÃO EM ADMINISTRAÇÃO, 22, 1998, Foz do Iguaçu. Anais. Foz do Iguaçu: ANPAD, 1998.

INSTITUTO BRASILEIRO DE GEOGRAFIA E ESTATÍSTICA. Sintese de indicadores sociais: uma análise de condições de vida da população brasileira. 2009. Disponível em: http://www.ibge.gov.br/home/estatistica/populacao/con- 
dicaodevida/indicadoresminimos/sinteseindicsociais2009/ indic_sociais2009.pdf. Acesso em 20.10.2012.

ISHERWOOD, B. O mundo dos bens: para uma antropologia do consumo. 1. ed., 2. reimpr. Rio de Janeiro: UFRJ, 2009b. 306 p.

JAISWAL, A. Fortune at the bottom of the pyramid: an alternative perspective. Ahmedabad: Indian Institute of Management, 2008. (Working paper n. 2007-07-13)

KARNANI, A. The mirage of marketing to the bottom of the pyramid: how the private sector can help alleviate poverty. California Management Review, v. 49, n. 4, p. 90-111, 2007a.

KARNANI, A. The BOP debate: Aneel Karnani responds. 2007b. Disponível em: http://www.nextbillion.net//blogs/2007/02/16/the-bop-debate-aneel-karnani-responds. Acesso em 15.01.2010.

KARNANI, A. Fighting poverty together: rethinking strategies for business, governments, and civil society to reduce poverty. New York: Palgrave Macmillan, 2011. 297 p.

KOTLER, P. What consumerism means for marketers. Harvard Business Review, v. 50, n. 3, p. 48-57, 1972.

LANDRUM, N. Advancing the 'base' of the pyramid debate. Strategic Management Review, v. 1, n. 1, p. 1-12, 2007.

LIMEIRA, T. O potencial do mercado de baixa renda. In: PARENTE, J; LIMEIRA, T; BARKI, E. Varejo para a baixa renda. Porto Alegre: Bookman, 2008. 200 p.

MATTOSO, C. Classes sociais, peculiaridades na base da pirâmide e a possibilidade de esquemas classificatórios. In: ENCONTRO NACIONAL DA ASSOCIAÇÃO NACIONAL DOS PROGRAMAS DE PÓS-GRADUAÇÃO EM ADMINISTRAÇÃO, 34, 2010, Rio de Janeiro. Anais. Rio de Janeiro: ANPAD, 2010.

MCCRACKEN, G. Cultura e consumo: novas abordagens ao caráter simbólico dos bens e das atividades de consumo. Rio de Janeiro: Mauad, 2003. 206 p.

MILLER, D. The poverty of morality. Journal of Consumer Culture, v. 1, n. 2, p. 225-243, 2001.

NERI, M. (Coord). A nova classe média: o lado brilhante dos pobres. Rio de Janeiro: FGV/IBRE, CPS, 2010. Disponível em: http://www.fgv.br/cps/ncm. Acesso em 16.10.2012.

NOGAMI, V; PACAGNAN, M. Consumo na base da pirâmide: uma análise bibliométrica do estado da arte na produção acadêmica no Brasil. In: ENCONTRO NACIONAL DA ASSOCIAÇÃO NACIONAL DOS PROGRAMAS DE PÓS-GRADUAÇÃO EM ADMINISTRAÇÃO, 35, 2011, Rio de Janeiro. Anais. Rio de Janeiro: ANPAD, 2011.

PRAHALAD, C. K. The fortune at the bottom of the pyramid: eradicating poverty through profits. New Jersey: Pearson Education, 2006a.

PRAHALAD, C. K. Prahalad responds to mirage at the bottom of the pyramid. 2006b. Disponivel em: http:// www.nextbillion.net/blog/2006/08/31/prahalad-responds-to-mirage-at-the-bottom-of-the-pyramid. Acesso em 15.01.2010.

PRAHALAD, C. K; HAMMOND, A. Serving the world's poor profitably. Harvard Business Review, v. 80, n. 9, p. 4-11, 2002.

PRAHALAD, C. K; HART, S. L. The fortune at the bottom of the pyramid. Strategy and Business, v. 26, p. 1-14, 2002.

ROCHA, E. Culpa e prazer: imagens do consumo na cultura de massa. Comunicação, Mídia e Consumo, v. 2, n. 3, p. 123-138, 2005.

ROCHA, E. Invisibilidade e revelação: camadas populares, cultura e práticas de consumo - apresentação. In: ROCHA, A; SILVA, J. (Orgs). Consumo na base da pirâmide: estudos brasileiros. Rio de Janeiro: Mauad X, 2009a. 255 p.

ROCHA, E. Os bens como cultura: Mary Douglas e a antropologia do consumo. In: DOUGLAS, M.; ISHERWOOD, B. O mundo dos bens: para uma antropologia do consumo. Rio de Janeiro: Ed UFRJ, 2006. p. 7-18.

SACHS, J. The end of poverty: economic possibilities for our time. New York: Penguin, 2005.

VEBlEn, T. A teoria da classe ociosa. São Paulo: Pioneira, 1965. $181 \mathrm{p}$.

WOOD, V; PITTA, D; FRANZAK, F. Successful marketing by multinational firms to the bottom of the pyramid: connecting share of heart, global "umbrella brands", and responsible marketing. Journal of Consumer Marketing, v. 25, n. 7, p. 419-429, 2008. 